\title{
On the relationship between growth and volatility
}

\author{
Keith Blackburn ${ }^{\mathrm{a}, *}$, Alessandra Pelloni ${ }^{\mathrm{b}}$ \\ ${ }^{a}$ Centre for Growth and Business Cycles Research, School of Economic Studies, University of Manchester, \\ Manchester M13 9PL, UK \\ ${ }^{\mathrm{b}}$ Department of Economics, University of Rome II, Italy \\ Received 19 March 2003; accepted 20 October 2003
}

\begin{abstract}
We study the relationship between output growth and output variability in a simple stochastic monetary growth model with nominal rigidities and learning-by-doing. We show that this relationship may be positive or negative depending on the impulse source of fluctuations.
\end{abstract}

(C) 2004 Elsevier B.V. All rights reserved.

Keywords: Business cycles; Growth; Volatility

JEL classification: E32; O42

\section{Introduction}

Recently, the question of how cyclical fluctuations might affect secular trends has been the subject of a growing body of literature. Of particular interest has been the relationship between short-run volatility and long-run growth. This relationship has been shown to depend on a number of factors, most notably the mechanism responsible for generating technological change and the parameters governing attitudes towards risk and uncertainty (e.g., Aghion and Saint-Paul, 1998a,b; Blackburn and Galindev, 2003; de Hek, 1999; Jones et al., 1999; Martin and Rogers, 1997, 2000). These insights have been established within the context of purely real models of the economy with real shocks and real propagation mechanisms. As far as we know, Dotsey and Sarte (2000) present the only analysis that explores the role of monetary factors. These authors develop a stochastic monetary growth model in which agents are subject to a cash-in-advance constraint, while operating a simple AK production technology with a fixed amount of labour. It is shown that a correlated increase in the mean and variance of monetary growth (or

\footnotetext{
* Corresponding author. Tel.: +44-161-275-3908; fax: +44-161-275-4928.

E-mail address: keith.blackburn@man.ac.uk (K. Blackburn).
} 
inflation) may cause either an increase or decrease in the mean of output growth due to offsetting effects through precautionary savings and inflation taxes. In what follows, we study the issue further using a quite different monetary growth model that allows for endogenous labour, multiple shocks, learning-by-doing and nominal rigidities. The last feature is accounted for by one-period nominal wage contracts. We show that the correlation between the mean and variance of output growth depends fundamentally on the impulse source of fluctuations (real shocks or nominal shocks). This new result suggests an alternative explanation for the conflicting empirical evidence on this relationship. ${ }^{1}$

\section{The model}

We consider an artificial economy in which there are constant populations (normalised to one) of identical, immortal households and identical, competitive firms. Naturally, the model is not meant to provide a complete account of the mechanisms underlying aggregate fluctuations, but rather is intended as an illustrative device for addressing the specific issue at hand. To this end, we focus and simplify the analysis by adopting the usual specifications of preferences and technologies that admit closed-form solutions. $^{2}$

The representative firm combines $N_{t}$ units of labour with $K_{t}$ units of capital to produce $Y_{t}$ units of output according to

$$
Y_{t}=\left(\bar{K}_{t} N_{t}\right)^{\alpha} K_{t}^{1-\alpha}, \quad \alpha \in(0,1),
$$

where $\bar{K}_{t}$ denotes the aggregate stock of capital, interpreted as a proxy for the stock of disembodied knowledge which is acquired through serendipitous learning-by-doing. Labour and capital are hired from households at the real wage rate $W_{t} / P_{t}$ and real rental rate $R_{t}$, respectively, where $W_{t}$ is the nominal wage and $P_{t}$ is the price of output. Profit maximisation implies

$$
\begin{aligned}
& \frac{W_{t}}{P_{t}}=\alpha \bar{K}_{t}^{\alpha} N_{t}^{\alpha-1} K_{t}^{1-\alpha}=\frac{\alpha Y_{t}}{N_{t}}, \\
& R_{t}=(1-\alpha) \bar{K}_{t}^{\alpha} N_{t}^{\alpha} K_{t}^{-\alpha}=\frac{(1-\alpha) Y_{t}}{K_{t}} .
\end{aligned}
$$

The representative household derives lifetime utility, $U$, according to

$$
U=\sum_{t=0}^{\infty} \beta^{t}\left[\gamma_{t} \log \left(C_{t}\right)+\theta \log \left(\frac{M_{t-1} \phi_{t}}{P_{t}}\right)-\lambda L_{t}\right], \quad \beta \in(0,1), \theta, \lambda>0,
$$

where $C_{t}$ denotes consumption, $M_{t-1} \phi_{t} / P_{t}$ denotes real money balances and $L_{t}$ denotes labour. Nominal cash balances at the beginning of each period, $M_{t-1}$, are augmented by a proportional monetary transfer, $\phi_{t}$. This transfer is an exogenous random variable, as is the term $\gamma_{t}$ which captures exogenous shifts in preferences (or in some underlying transactions or home production technology). Both types of

\footnotetext{
1 See Kneller and Young (2001).

2 That is, utility functions are logarithmic and production functions are Cobb-Douglas. More general specifications would require the use of numerical simulations which might be worthwhile exercises to undertake in future research. The full derivation of the solutions is available on request from the authors.
} 
disturbance act as demand shocks - $\phi_{t}$ a nominal shock and $\gamma_{t}$ a real shock — and are governed by independent, stationary stochastic processes with constant means, $\mu_{\phi}$ and $\mu_{\gamma}$, and constant variances, $\sigma_{\phi}^{2}$ and $\sigma_{\gamma}^{2}{ }^{3}$ Each household maximises the expected value of intertemporal utility in Eq. (4) subject to the sequence of budget constraints,

$$
C_{t}+\frac{M_{t}}{P_{t}}+A_{t+1}=\frac{W_{t}}{P_{t}} L_{t}+\frac{M_{t-1} \phi_{t}}{P_{t}}+R_{t} A_{t} .
$$

where $A_{t}$ denotes real assets. The first-order conditions for consumption, money balances and asset holdings imply

$$
\begin{aligned}
& \frac{\gamma_{t}}{C_{t}}=\beta E_{t}\left(\frac{\gamma_{t+1} R_{t+1}}{C_{t+1}}\right) \\
& \frac{\gamma_{t}}{P_{t} C_{t}}=\beta \theta \frac{1}{M_{t}}+\beta E_{t}\left(\frac{\gamma_{t+1} \phi_{t+1}}{P_{t+1} C_{t+1}}\right) .
\end{aligned}
$$

where $E_{t}$ is the expectations operator. As regards hours of work, we assume that the labour market is characterised by monopolistic unions that choose a nominal wage at which households supply whatever labour is demanded by firms. We also assume that wage setting takes place prior to the realisations of shocks on the basis of one-period contracts. The contract wage is chosen so as to maximise households' expected utility, given firms' labour demand. The optimal wage set at the end of period $t-1$ for period $t$ satisfies

$$
\lambda E_{t-1}\left(N_{t}\right)=\alpha W_{t} E_{t-1}\left(\frac{\gamma_{t} N_{t}}{P_{t} C_{t}}\right) .
$$

The behaviour of the household is completed by imposing the transversality conditions $\lim _{\tau} \rightarrow$ ${ }_{\infty} \beta^{\tau} E_{t}\left(\gamma_{t+\tau} M_{t+\tau} / P_{t+\tau} C_{t+\tau}\right)=\lim _{\tau \rightarrow \infty} \beta^{\tau} E_{t}\left(\gamma_{t+\tau} A_{t+\tau+1} / C_{t+\tau}\right)=0$.

\section{General equilibrium}

The full solution of the model is obtained by combining the relationships obtained so far with the relevant market clearing conditions. These conditions are $C_{t}+K_{t+1}=Y_{t}$ (for goods), $K_{t}=A_{t}$ (for capital), $N_{t}=L_{t}$ (for labour) and $M_{t}=H_{t}$ (for money), where $H_{t}$ denotes the nominal money supply which evolves according to $H_{t}=\phi_{t} H_{t-1}$.

\footnotetext{
3 We also assume that the shocks are bounded within some positive interval such that the constraint on labour hours is satisfied as well. For simplicity, we suppose that agents derive linear utility from labour, either because they derive linear utility from leisure, or because labour is indivisible and determined by employment lotteries. For further simplicity, we abstract from technology shocks since these shocks have been dealt with at length in the existing literature.
} 
The equilibrium decision rules for consumption, capital and cash balances are given respectively by

$$
\begin{aligned}
& C_{t}=\frac{(1-\pi) \gamma_{t}}{(1-\pi) \gamma_{t}+\pi \mu_{\gamma}} Y_{t}, \\
& K_{t+1}=\frac{\pi \mu_{\gamma}}{(1-\pi) \gamma_{t}+\pi \mu_{\gamma}} Y_{t}, \\
& \frac{M_{t}}{P_{t}}=\frac{(1-\pi) \beta \theta}{(1-\beta)\left[(1-\pi) \gamma_{t}+\pi \mu_{\gamma}\right]} Y_{t},
\end{aligned}
$$

where $\pi=(1-\alpha) \beta$. Thus, consumption increases, investment decreases and money demand decreases in response to higher realisations of the preference shock, $\gamma_{t}$. Note that the output share of consumption (investment) is a concave (convex) function of this shock so that the average share is a decreasing (increasing) function of the variance of the shock. ${ }^{4}$ This is due to the positive effect of uncertainty on the precautionary demand for savings. The equilibrium level of employment is given by

$$
N_{t}=\frac{\alpha^{2}\left[(1-\pi) \gamma_{t}+\pi \mu_{\gamma}\right] \phi_{t}}{\lambda(1-\pi) \mu_{\phi}}
$$

Thus, employment depends positively on both real and nominal shocks. The latter, $\phi_{t}$, has real effects due to the presence of nominal wage contracts which imply that (unanticipated) monetary fluctuations are non-neutral.

Given the above, we may establish the stochastic, endogenous growth rate of output. From Eqs. (1), (10) and (12), we have

$$
\frac{Y_{t+1}}{Y_{t}}=\frac{\alpha^{2 \alpha} \pi \mu_{\gamma}\left[(1-\pi) \gamma_{t+1}+\pi \mu_{\gamma}\right]^{\alpha} \phi_{t+1}^{\alpha}}{\lambda^{\alpha}(1-\pi)^{\alpha} \mu_{\phi}^{\alpha}\left[(1-\pi) \gamma_{t}+\pi \mu_{\gamma}\right]} .
$$

The mean and variance of this growth rate can be approximated as

$$
\begin{aligned}
& \operatorname{Mean}\left(\frac{Y_{t+1}}{Y_{t}}\right) \simeq \psi\left(1+\frac{(1-\pi)^{2}[\alpha(\alpha-1)+2]}{2 \mu_{\gamma}^{2}} \sigma_{\gamma}^{2}+\frac{\alpha(\alpha-1)}{2 \mu_{\phi}^{2}} \sigma_{\phi}^{2}\right), \\
& \operatorname{Var}\left(\frac{Y_{t+1}}{Y_{t}}\right) \simeq \psi^{2}\left(\frac{(1-\pi)^{2}\left(\alpha^{2}+1\right)}{\mu_{\gamma}^{2}} \sigma_{\gamma}^{2}+\frac{\alpha^{2}}{\mu_{\phi}^{2}} \sigma_{\phi}^{2}\right),
\end{aligned}
$$

where $\psi=\pi\left[\alpha^{2} \mu_{\gamma} / \lambda(1-\pi)\right]^{\alpha}$.

Evidently, both $\operatorname{Mean}\left(Y_{t+1} / Y_{t}\right)$ and $\operatorname{Var}\left(Y_{t+1} / Y\right)$ are increasing in $\sigma_{\gamma}^{2}$, the variance of the real (preference) shock. In terms of Eq. (13), the actual growth rate of output is convex in the lagged

\footnotetext{
4 This is merely an example of the well-known result that the expected value of a convex (concave) function of a variable is increased (decreased) by a mean-preserving spread of that variable.
} 
realisations of this shock, but concave in the current realisations of the shock. The former property is a reflection of the convexity in savings behaviour, alluded to earlier, which is transmitted linearly to production via the process of learning-by-doing. The latter property is a symptom of diminishing returns to labour which convert linear employment responses into non-linear output effects. An increase in $\sigma_{\gamma}^{2}$ has a positive impact on $\operatorname{Mean}\left(Y_{t+1} / Y_{t}\right)$ through the savings channel which more than offsets the negative impact on Mean $\left(Y_{t+1} / Y_{t}\right)$ through the employment channel so that the net result is an increase in the average growth rate of output. It follows that a higher value of $\sigma_{\gamma}^{2}$ will generate a positive correlation between secular growth and cyclical volatility. By contrast, Mean $\left(Y_{t+1} / Y_{t}\right)$ decreases, while $\operatorname{Var}\left(Y_{t+1} / Y\right)$ increases, with an increase in $\sigma_{\phi}^{2}$, the variance of the nominal (monetary growth) shock. From Eq. (13), the actual growth rate of output is a concave function of this shock, reflecting its (linear) effect on employment due to nominal wage contracts and the property of diminishing returns to labour. Consequently, a higher value of $\sigma_{\phi}^{2}$ will generate a negative correlation between long-run growth and short-run volatility. ${ }^{5}$

In summary, our analysis predicts that the relationship between output growth and output variability depends fundamentally on the source of stochastic fluctuations in the economy. This relationship may be positive or negative according to whether real or nominal shocks predominate. Such a result has not, to our knowledge, been established before. From an empirical perspective, our analysis may be seen as providing a further explanation for the lack of robust evidence on the relationship.

\section{Acknowledgements}

The authors are grateful for the financial support of the Leverhulme Trust and the ESRC (grant no. L138251030). The usual disclaimer applies.

\section{References}

Aghion, P., Saint-Paul, G., 1998a. On the virtue of bad times: an analysis of the interaction between economic fluctuations and productivity growth. Macroeconomic Dynamics 2, 322-344.

Aghion, P., Saint-Paul, G., 1998b. Uncovering some causal relationships between productivity growth and the structure of economic fluctuations: a tentative survey. Labour 12, 279-303.

Blackburn, K., Galindev, R., 2003. Growth, volatility and learning. Economics Letters 79, 417-421.

de Hek, P.A., 1999. On endogenous growth under uncertainty. International Economic Review 40, $727-744$.

Dotsey, M., Sarte, P.D., 2000. Inflation uncertainty and growth in a cash-in-advance economy. Journal of Monetary Economics $45,631-655$.

Jones, L.E., Manuelli, R.E., Stacchetti, E., 1999. Technology (and policy) shocks in models of endogenous growth. NBER Working Paper No. 7063

Kneller, R., Young, G., 2001. Business cycle volatility, uncertainty and long-run growth. Manchester School 69, 534-552.

Martin, P., Rogers, C.A., 1997. Stabilisation policy, learning-by-doing and economic growth. Oxford Economic Papers 49, $152-166$.

Martin, P., Rogers, C.A., 2000. Long-term growth and short-term economic instability. European Economic Review 44, $359-381$.

Temple, J., 2000. Inflation and growth: stories short and tall. Journal of Economic Surveys 14, 395-426.

5 This result is consistent with the majority view that nominal uncertainty is bad for growth. Like Dotsey and Sarte (2000), we are able to obtain a more ambiguous effect by assuming that the mean and variance of money growth are positively correlated. In our case, however, an increase in $\mu_{\phi}\left(\sigma_{\phi}^{2}\right)$ tends to raise (lower) Mean $\left(Y_{t+1} / Y_{t}\right)$, rather than vice versa. For a recent survey of the money and growth literature, see Temple (2000). 